\title{
Novel Surface Modification of Sulfur by Plasma Polymerization and its Application in Dissimilar Rubber-Rubber Blends
}

\author{
Rui Guo $\cdot$ Auke G. Talma $\cdot$ Rabin N. Datta $\cdot$ Wilma K. Dierkes • \\ Jacques W. M. Noordermeer
}

Received: 25 January 2010/Accepted: 5 July 2010/Published online: 21 July 2010

(C) The Author(s) 2010. This article is published with open access at Springerlink.com

\begin{abstract}
In this study, surface modification of elemental sulfur by plasma polymerization with acetylene, perfluorohexane and acrylic acid is described, with the aim of changing the surface properties of sulfur without losing the bulk properties and reactivities in the vulcanization process. Significant improvements are obtained in dissimilar elastomer blends using the encapsulated sulfur powders. The conditions for the plasma polymerization were varied in order to obtain the optimal performance of the modified sulfur. The imperfections in the shell structure, obtained with plasma polymers, act as gateways to release sulfur for the vulcanization reaction.
\end{abstract}

Keywords Plasma polymerization - Sulfur · Rubber blends · Vulcanization · Surface polarity

\section{Introduction}

Sulfur is the first and still most often used curing agent in the rubber industry. A problem involved in the application of sulfur in dissimilar rubber/rubber blends is the difference in solubility of sulfur in the different rubber phases. During the mixing and vulcanization processes, sulfur migrates across phase boundaries due to solubility differences. A cure mismatch, as a result of uneven distribution of curatives, leads to an unbalanced distribution of crosslinks in each phase and in this way deteriorates the properties of the blend. A few methods for adjusting the amount of curatives in the different phases are described in literature: (1) modification of the elastomers; (2) modifing the surface characteristics of the fillers, e.g. by encapsulation; and (3) adjusting the mixing procedure [1-4].

Plasma polymerization as a surface modification technique, can deposit a highly crosslinked ultra-thin film on a substrate in a gas phase and clean process. It is expected that the encapsulation of a powdery substrate with a layer of highly crosslinked plasma

R. Guo · A. G. Talma · R. N. Datta · W. K. Dierkes · J. W. M. Noordermeer $(\bowtie)$

Faculty of Engineering Technology, Department of Elastomer Technology and Engineering,

University of Twente, P.O. Box 217, 7500AE Enschede, The Netherlands

e-mail: j.w.m.noordermeer@utwente.nl 
polymer retains the bulk properties of the substrate, while selectively modifying the surface tension, polarity, morphology and electrical conductivity [5, 6].

Several studies were performed on the surface modification of carbon black and silica, using plasma treatment. The deposition of a plasma polymer layer on filler can reduce the filler-filler interaction and enhance the filler-polymer interaction, respectively [7-16]. It was found that carbon black is much more difficult to be treated by plasma polymerization compared to silica as there are less functional groups on the carbon black surface [12, 13]. Being different from reinforcing fillers, sulfur has a higher density and the application of plasma polymer encapsulated sulfur is even more complicated, as the encapsulated sulfur needs to be released from inside its shell to take part in the vulcanization process.

Van Ooij and Vidal et al. [17, 18] have applied plasma polymerization on curatives and checked their reactivity towards squalene in model compound studies. In the present study, plasma polymerizations of acetylene, perfluorohexane and acrylic acid are carried out on pre-ground curing agent: sulfur, in a Radio Frequency (RF) plasma vertical tubular reactor. The aim of the study was to modify the surface properties of sulfur using these different monomers in order to improve the distribution of sulfur and subsequently improve the co-vulcanization and mechanical properties of dissimilar rubber/rubber blends.

\section{Experimental Part}

\section{Materials}

The following types of rubber were employed: Solution Styrene-Butadiene rubber (S-SBR, Buna $^{\circledR}$ VSL 5025-0HM from LANXESS Corp., Germany), Nitrile-Butadiene rubber (NBR, Perbunan ${ }^{\circledR}$ 3446F from LANXESS Corp.), and Ethylene Propylene Diene rubber (EPDM, Keltan ${ }^{\circledR} 4703$ from DSM Elastomers, the Netherlands). Zinc oxide was purchased from Sigma-Aldrich; stearic acid was used as commercial grade also from Sigma-Aldrich, and accelerator N-cyclohexylbenzothiazole-2-sulfenamide (CBS) (Santocure ${ }^{\circledR}$ CBS) was provided by Flexsys, Belgium. Elemental sulfur $\left(\mathrm{S}_{8}\right)$ was purchased from Sigma-Aldrich, with a particle size smaller than 100 mesh. The following monomers for plasma treatment: Acetylene (99.6\% purity) was supplied by Matheson tri gas, USA; Perfluorohexane $(99.6 \%$ purity) and Acrylic acid (99\% purity) were both purchased from Sigma-Aldrich.

\section{Methods}

\section{Grinding by Ball Mill}

The sulfur powders were ground using a ball mill and the powders were sieved to a size smaller than $50 \mu \mathrm{m}$ before the plasma treatment.

\section{Plasma Polymerization}

To have a powder-like substrate modified completely by plasma polymerization, special reactor designs are required to prevent agglomeration of the powders and to make sure that each particle is exposed to the plasma. The plasma polymerizations on pre-ground sulfur were carried out in a vertical tubular reactor. A schematic representation of this reactor is shown in Fig. 1. The plasma chamber is made of Pyrex glass, which consists of a flat bottom flask connected to a long cylindrical tube and closed with a glass lid with a valve on 

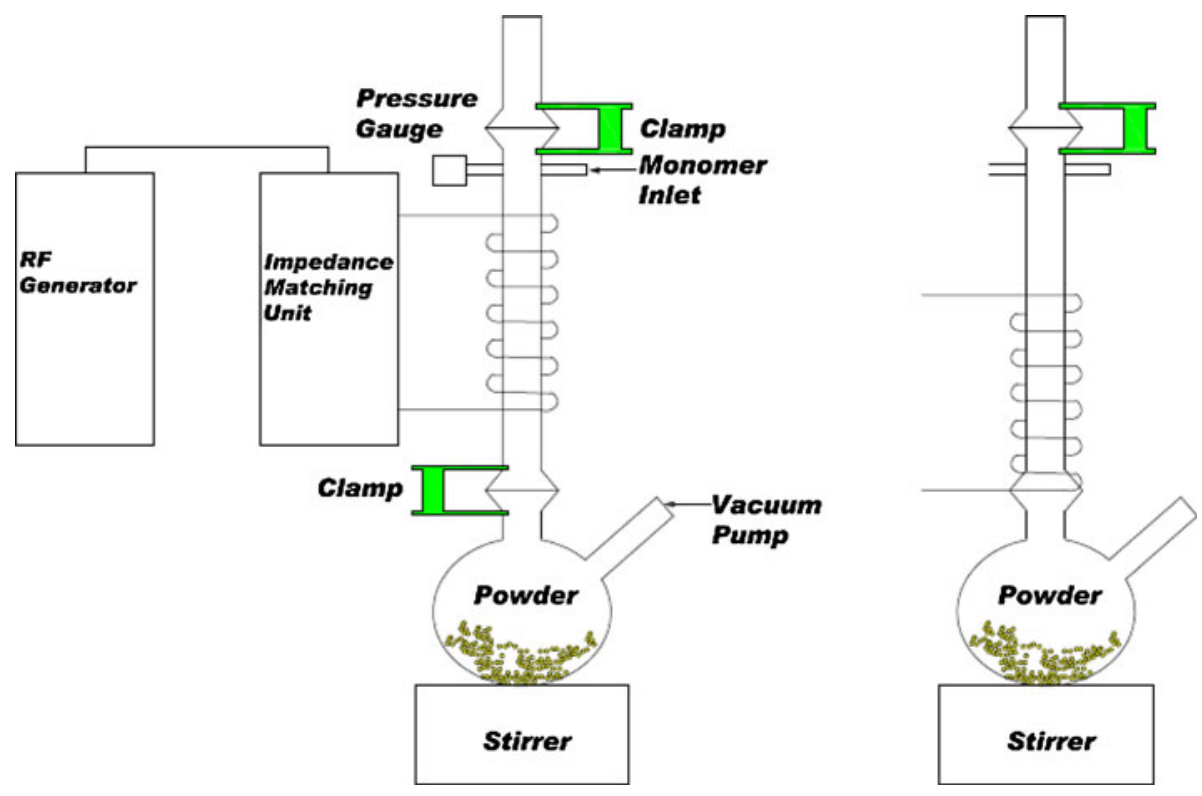

Fig. 1 a Schematic representation of a vertical tubular RF plasma reactor with coil position 1; $\mathbf{b}$ coil position 2

the top. The round bottom flask has an outlet for the vacuum pump. There are two inlets on the top of the tubular region. One slot is for connection to the monomer source, and the other for the pressure gauge. The tubular part is surrounded by a copper coil, which is maintained in a Faraday cage to avoid electromagnetic radiation.

The amount of sulfur to be treated was fixed at 20 grams for each batch. The glass reactor was evacuated using an oil pump to a pressure of 3.6 Pa. Subsequently, the monomer gas or vapor was introduced under steady flow conditions and the monomer pressure was maintained at approximately $26-31 \mathrm{~Pa}$. Finally, the coil was brought down to position 2 and a discharge power (13.56 MHz frequency) was applied, which turned the monomer gas into the plasma state. Subsequently, plasma polymerization took place and a plasma polymer layer was deposited on the sulfur substrate. The reaction conditions are summarized in Table 1.

Sulfur has the tendency of becoming plasticized and forming lumps during mixing. To obtain an optimal mixing effect of sulfur, a special design of a triangle-shaped magnetic stirrer bound with three flexible plastic tubes with different lengths seemed to provide the best mixing effect. The longest tube had the length of the diameter of the bottom of the reaction flask. The stirrer works as a broom and the powders are all the time being swept to the plasma.

\section{Scanning Electron Microscopy (SEM)}

Digital images were obtained for both untreated and plasma treated sulfur, deposited on carbon tape, using a LEO 1550 FEG/Thermo Noran Instruments. The cross-sections of plasma acetylene coated $\mathrm{S}_{8}\left(\mathrm{PPAS}_{8}\right)$ were created using a sharp knife, cutting through the sulfur agglomerates under a stereo light microscope. As the size of agglomerates of plasma perfluorohexane coated $\mathrm{S}_{8}\left(\mathrm{PFHS}_{8}\right)$ and plasma acrylic acid coated $\mathrm{S}_{8}\left(\mathrm{PAAS}_{8}\right)$ were too 
Table 1 Operational conditions for plasma polymerization with different monomers

\begin{tabular}{llllll}
\hline Sample code & Monomer & RF power (W) & Monomer pressure (Pa) & Flow rate (sccm) & Reaction time (h) \\
\hline PPAS $_{8}-1$ & Acetylene & 150 & 31 & 20 & 1 \\
PPAS $_{8}-2$ & & 150 & 26 & 20 & 1.5 \\
PPAS $_{8}-3$ & 125 & 26 & 20 & 1.5 \\
PFHS $_{8}-1$ & Perfluoro- & 180 & 27 & - & 1 \\
PFHS $_{8}-2$ & Hexane & 180 & 27 & - & 1.5 \\
PAAS $_{8}-1$ & Acrylic acid & 180 & 27 & - & 1.5 \\
PAAS $_{8}-2$ & & 180 & 27 & & - \\
\hline
\end{tabular}

small to be cut with a knife, their cross-sections were created by crushing the sulfur powders placed on top of a glass sample holder for light microscopy, with another glass plate sliding over it.

\section{Wetting Behaviors with Liquids of Known Surface Energy}

Glycerol, formamide, ethylene glycol, toluene and n-hexane were used as the comparative liquids. For this analysis, about $50 \mathrm{ml}$ of liquids were put in a beaker and $1 \mathrm{~g}$ of untreated or treated sulfur was added to the liquids. The powder sample sinks if it has a surface tension higher than that of the liquid; otherwise it floats on the liquid.

\section{Thermogravimetric Analysis (TGA)}

A Perkin Elmer TGA 7 was used to determine the amount of plasma modified material on the surface coated samples. For a qualitative measurement of the amount of plasma coating, the samples were heated in a nitrogen atmosphere from 50 to $700^{\circ} \mathrm{C}$ with a heating rate of $10^{\circ} \mathrm{C} / \mathrm{min}$. The obtained weight loss characteristics of the plasma polymer treated sulfur-samples were compared to the untreated sulfur. The quantitative measurement of the amount of coating was carried out by heating in a nitrogen atmosphere from 50 to $180^{\circ} \mathrm{C}$, followed by an isothermal step at $180^{\circ} \mathrm{C}$ for $5 \mathrm{~h}$ to complete the sublimation of the sulfur. The remaining weight was determined as the plasma polymer coating.

\section{Time-of-Flight Secondary Ion Mass Spectroscopy (ToF-SIMS)}

After the plasma treatment, the untreated and the different plasma polymer treated sulfursamples were examined by a CAMECA ION-ToF spectrometer (ToF-SIMS IV). The instrument was equipped with a reflection-type time-of-flight mass analyser and a pulsed $25 \mathrm{kV}$ primary source of mono-isotopic $69 \mathrm{Ga}^{+}$ions, with a minimum beam size of $50 \mathrm{~nm}$. Positive and negative spectra were collected at $25 \mathrm{kV}$ primary ion energy, a pulse width of $25 \mathrm{~ns}$ and a total integrated ion dose of $\sim 10^{11}$ ions $/ \mathrm{cm}^{2}$. A sputter gun was also applied to eliminate the impurity ions from the atmosphere.

\section{Rubber Mixing and Testing}

The formulations used for this study are given in Table 2. SE and NE are the abbreviations for the 50/50 w/w SBR/EPDM and 50/50 w/w NBR/EPDM blends, respectively. The mixing was carried out in a Brabender Plasticorder internal mixer with a chamber volume 
Table 2 Compound formulations in phr

\begin{tabular}{lll}
\hline Component & SE & NE \\
\hline SBR & 50 & 0 \\
NBR & 0 & 50 \\
EPDM & 50 & 50 \\
ZnO & 5 & 5 \\
Stearic acid & 2 & 2 \\
Sulfur & 2.5 & 2.5 \\
CBS & 1.7 & 1.7 \\
\hline
\end{tabular}

of $390 \mathrm{ml}$ for $10 \mathrm{~min}$ in total. The starting temperature was $50^{\circ} \mathrm{C}$, the rotor speed $70 \mathrm{rpm}$, and a load factor of $70 \%$ was applied. Zinc-oxide and stearic acid were added into the internal mixer after 5 min mixing of the rubber or rubber blends. The compounds were dropped after the full 10 min onto a Schwabenthan two roll mill $(15 \times 33 \mathrm{~cm}$, Polymix 80) with a friction ratio of $1: 1.25$, cooled and slabbed. The second mixing step was performed on the same two roll mill for about $10 \mathrm{~min}$ with a finishing temperature around $40^{\circ} \mathrm{C}$. The curing properties of the compounds and the curing time $t_{95}$ were determined at $160^{\circ} \mathrm{C}$ using a rheometer (RPA 2000) from Alpha Technologies. Vulcanization was carried out in a compression molding Wickert laboratory press (WLP $1600 / 5 * 4 / 3$ ) at $160^{\circ} \mathrm{C}$, for a time period of $t_{95}$. Stress-strain properties were determined using a Zwick Z 1.0/TH1S tensile tester according to the ISO 37 standard.

\section{Results and Discussion}

The appearance of the plasma polymer treated sulfur varied according to the monomer applied. For plasma acetylene treated sulfur, a brownish color was obtained. The plasma perfluorohexane treated sulfur did not give an appreciable difference in color while the plasma acrylic acid treated sulfur had a brighter yellow color and a strong smell from acrylic acid.

\section{Scanning Electron Microscopy (SEM)}

The morphologies of the ground uncoated sulfur and the plasma polymer modified sulfur particles are shown in Fig. 2a-d. Compared to the image of uncoated sulfur, Fig. 2a, a different structure is observed in Fig. $2 \mathrm{~b}-\mathrm{d}$. The sulfur agglomerates after the plasma polymerization with acetylene, perfluorohexane and acrylic acid are rougher, as an amorphous layer is deposited on the outside. The size of the encapsulated particles ranges from 10 to $100 \mu \mathrm{m}$. Different from what has been described in the literature, $[5,6,18]$ the skin-layer is not free of pin-holes. Instead, there are quite some flaws present. As sulfur needs to be released from the shell before the vulcanization process in a rubber system, the flawed encapsulation is actually a gateway for future release of the active sulfur.

A core-shell structure of encapsulated sulfur aggregates with the three monomers is shown in Fig. 3a-c, which represent cross-sections with about $100 \mathrm{~nm}$ thickness of the deposited plasma polymer layer. The plasma polymer layer in Fig. 3a is more coherent; while in Fig. 3b, the deposited layer is more rough and looks like deposited dots. The especially loose structure in Fig. $3 \mathrm{c}$ is most probably due to the formation of elemental fluor which etches the layer. 

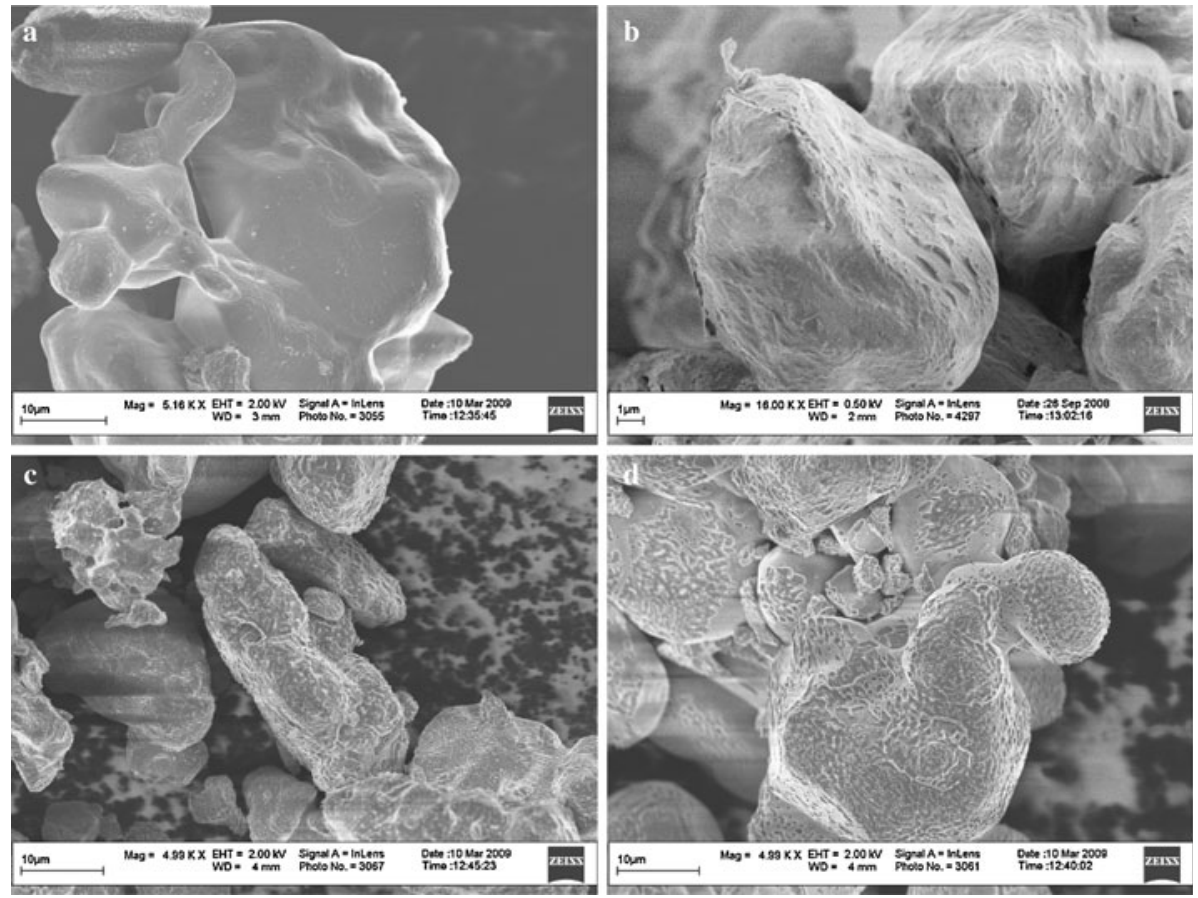

Fig. 2 SEM images: a uncoated sulfur; b $\mathrm{PPAS}_{8} ; \mathbf{c} \mathrm{PFHS}_{8} ; \mathbf{d} \mathrm{PAAS}_{8}$

\section{Surface Energies}

The surface energies of the rubber polymers involved in this study were calculated by the following methods. The surface energy of polystyrene is given as $43 \mathrm{~mJ} / \mathrm{m}^{2}$ and that of polybutadiene as $32.5 \mathrm{~mJ} / \mathrm{m}^{2}$ in literature [19]. In method 1, the surface energy was calculated on basis of the weight ratio of styrene and butadiene in SBR, the surface energy of SBR was estimated to be $34.1 \mathrm{~mJ} / \mathrm{m}^{2}$. The surface energies of EPDM and NBR were derived in the same way and are given in Table 3. In method 2, the surface energies were calculated from the parachor per structural unit by applying (1) according to the method described by Van Krevelen and Hoftijzer [19].

$$
\gamma=\left(\frac{P_{s}}{V}\right)^{4}
$$

In this equation, $P_{s}$ is the parachor with a unit of $\left(\mathrm{m}^{3} / \mathrm{mol}\right) \times\left(\mathrm{J} / \mathrm{m}^{2}\right)^{1 / 4}$ and $V$ is the molar volume of a particular atom or structure. The calculated surface energies are also summarized in Table 3 . The average values of the surface energies from the two methods are used for further discussion.

After the plasma surface modification with different monomers, sulfur floats on top of ethylene glycol, while the untreated sulfur sinks immediately. The surface energy of uncoated sulfur is therefore higher than that of ethylene glycol (47.7). Its surface energy is scaled in the range of 47.7 to $58 \mathrm{~mJ} / \mathrm{m}^{2}$ as it still floats on formamide. As all plasma polymer-encapsulated sulfurs sink immediately in toluene, their surface energies are all in the range of 28.4 to $47.7 \mathrm{~mJ} / \mathrm{m}^{2}$ as indicated in Fig. 4. Polyperfluorohexane coated sulfur 

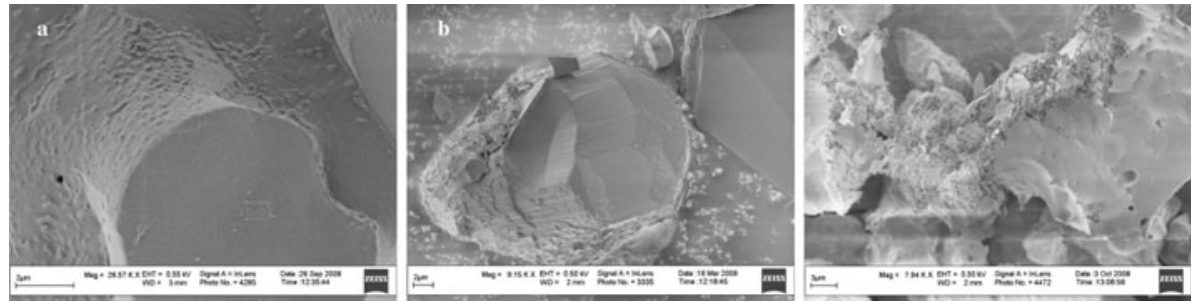

Fig. 3 SEM images: cross-section of the plasma coated sulfur with: a Polyacetylene; b Polyacrylic acid; c Polyperfluorohexane

Table 3 Surface energies of SBR, EPDM and NBR $\left(\mathrm{mJ} / \mathrm{m}^{2}\right)$

\begin{tabular}{llll}
\hline Polymer & $\gamma_{w}$ from weight ratio & $\gamma_{p}$ from parachor & $\bar{\gamma}$ average \\
\hline SBR & 34.1 & 29.7 & 31.9 \\
EPDM & 32.0 & 29.0 & 30.5 \\
NBR & 44.5 & 41.9 & 43.2 \\
\hline
\end{tabular}

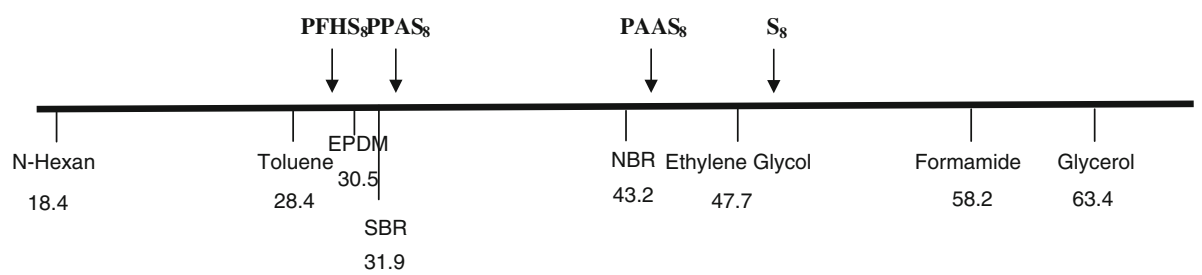

Fig. 4 Surface energies of uncoated and different plasma polymer encapsulated sulfurs $\left(\mathrm{mJ} / \mathrm{m}^{2}\right)$

$\left(\mathrm{PFHS}_{8}\right)$ floats on ethylene glycol for hours, while sulfur-samples coated with the other two polymers sink after minutes, esp. acrylic acid coated sulfur $\left(\mathrm{PAAS}_{8}\right)$. This means that the surface energy of $\mathrm{PFHS}_{8}<\mathrm{PPAS}_{8}<\mathrm{PAAS}_{8}$. It all indicates that, as the surface energy of sulfur after encapsulation with a plasma polymer layer is brought closer to those of the rubbers, better compatibility with these rubbers is to be expected. The surface energies in Fig. 4 are semi-quantitive, however, they are helpful in predicting compatibility.

\section{Thermogravimetric Analysis (TGA)}

The thermogravimetric curves of uncoated sulfur and sulfur encapsulated with different plasma polymers are given in Fig. 5. The weight losses in the TGA curves of the different encapsulated sulfur powders are all shifted to a higher temperature compared to uncoated sulfur. The amounts of deposition and the temperatures for $5 \%$ weight loss are summarized in Table 4. Amongst the three monomers used in the study, acetylene is the easiest to form a plasma polymer, where a RF power of only 125 or $150 \mathrm{~W}$ was sufficient to create the plasma state. Polyacetylene also provides the largest delay in weight loss, the highest $5 \%$ wt. loss temperature. The smallest delay is seen for plasma perfluorohexane treated sulfur even if it has a larger amount of deposition. The very porous and loose structure of the plasma layer may account for this lowest protection against weight loss. 
Fig. 5 TGA thermograms of uncoated and plasma polymers coated sulfurs. ( -$) \mathrm{S}_{8}$; $\left(\square \square-\right.$ PPAS $_{8}-2 ;(\multimap-)$ $\mathrm{PFHS}_{8}-2 ;(\triangle) \mathrm{PAAS}_{8}-2$
Table 4 Estimated coating amount (wt\%) and 5\% wt loss temperature for plasma polymer encapsulated sulfur samples

$N A$ not available

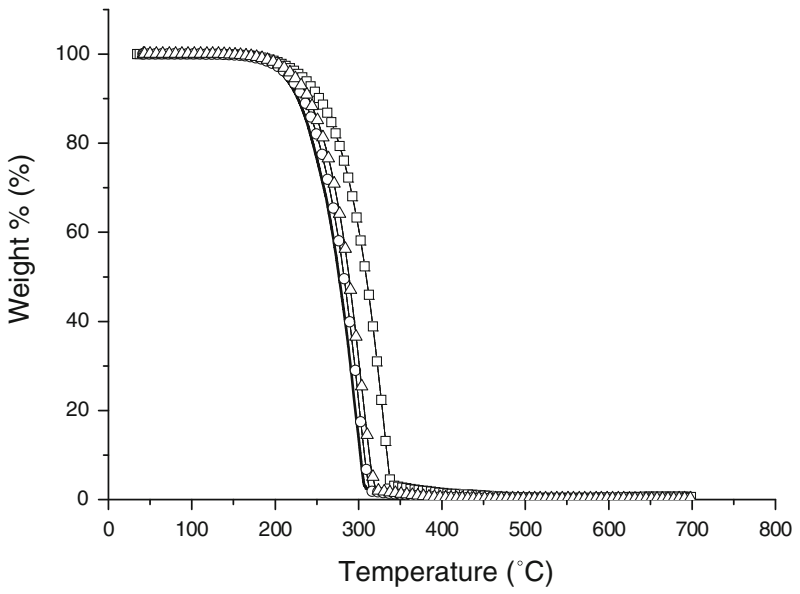

\begin{tabular}{lll}
\hline Sample code & $\begin{array}{l}\text { Amount of } \\
\text { coating }(\%)\end{array}$ & $\begin{array}{l}\text { Temperature at } \\
5 \% \text { wt loss }\end{array}$ \\
\hline $\mathrm{S}_{8}$ & - & 211.0 \\
PPAS $_{8}-1$ & NA & 231.5 \\
PPAS $_{8}-2$ & 1.32 & 235.0 \\
PPAS $_{8}-3$ & 1.51 & 231.4 \\
PFHS $_{8}-1$ & 1.23 & 211.2 \\
PFHS $_{8}-2$ & 4.97 & 216.8 \\
PAAS $_{8}-1$ & 1.4 & 214.5 \\
PAAS $_{8}-2$ & 2.2 & 222.5 \\
\hline
\end{tabular}

\section{ToF-SIMS}

ToF-SIMS was applied to both the untreated sulfur and the plasma polymer encapsulated sulfur to obtain structural information on the outermost layer of the samples. The positive and negative spectra of untreated sulfur are presented in Fig. 6a and b, respectively. Compared to Fig. 6b, there are clearly more peaks in the positive spectra, in Fig. 6a, coming from hydrocarbon ions in the low molecular weight range. It is interesting to see that sulfur forms almost identical characteristic peaks of $S_{1}, S_{2} \ldots$ up to $S_{11}$ in both the positive and the negative spectra.

The positive and negative spectra of plasma polyacetylene treated sulfur $\left(\mathrm{PPAS}_{8}-2\right)$ are given in Fig. 7a and b, respectively. In the positive spectra in Fig. 7a, higher intensities are shown for the hydrocarbon peaks compared to the sulfur peaks in the low mass range from 0 to 200, while in Fig. 6a, the intensity of sulfur is much higher than those of hydrocarbons. In Fig. 7, the intensities of all sulfur peaks are decreased in all mass ranges, which proves that the sulfur substrate is covered, however not to the full $100 \%$. In the high mass range, specific peak patterns can be observed, which prove the presence of plasma polyacetylene. Not much difference was obtained in the negative spectra in Fig. 7b, where only more noise peaks are seen in the high mass range of 200 to 400.

The positive spectra of plasma polyperfluorohexane treated sulfur $\left(\mathrm{PFHS}_{8}-2\right)$ are shown in Fig. 8a. Similar changes are obtained as those in Fig. 7a compared to the untreated 

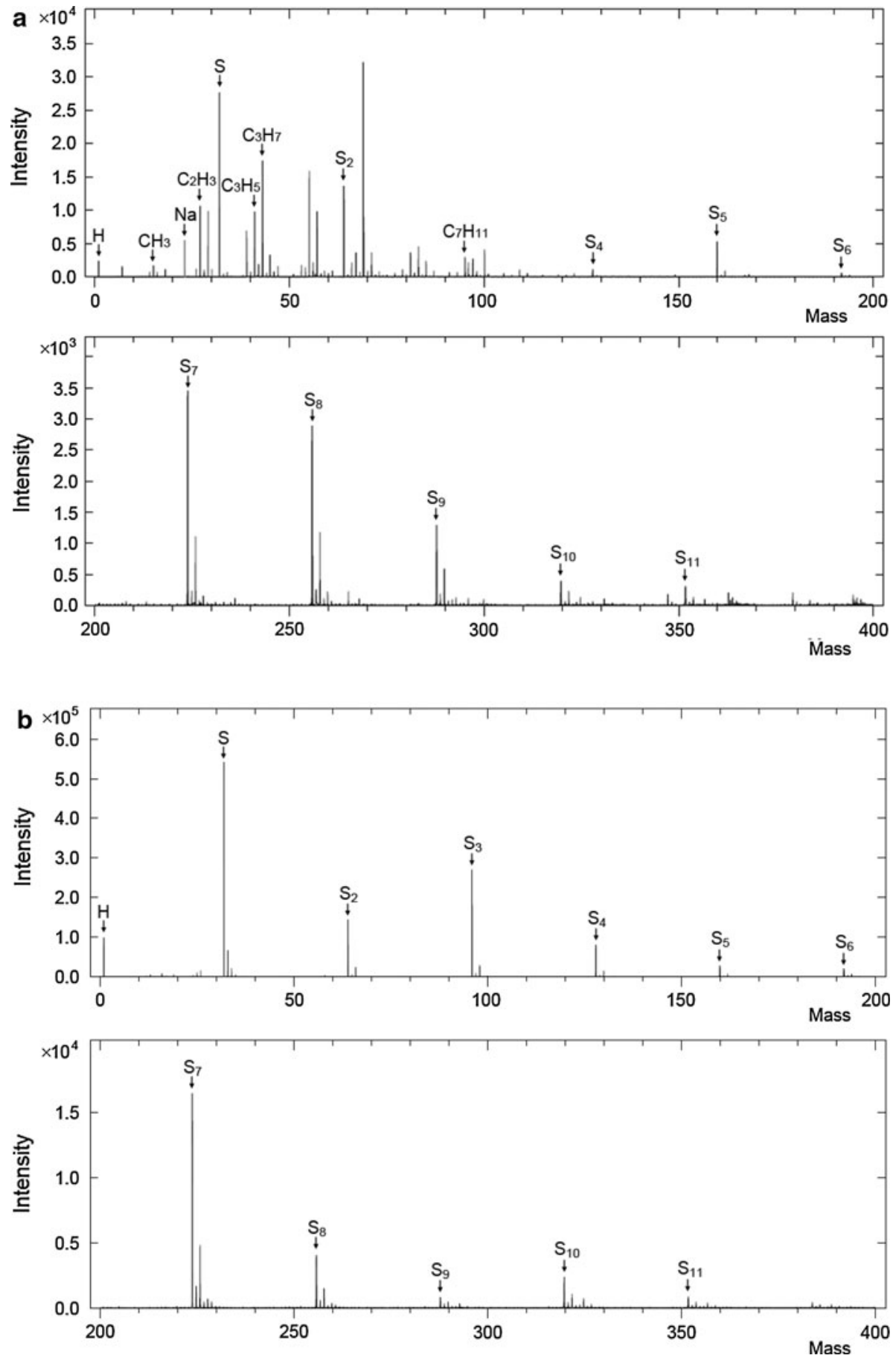

Fig. 6 a Positive ToF-SIMS spectrum of untreated sulfur; b negative ToF-SIMS spectrum of untreated sulfur 

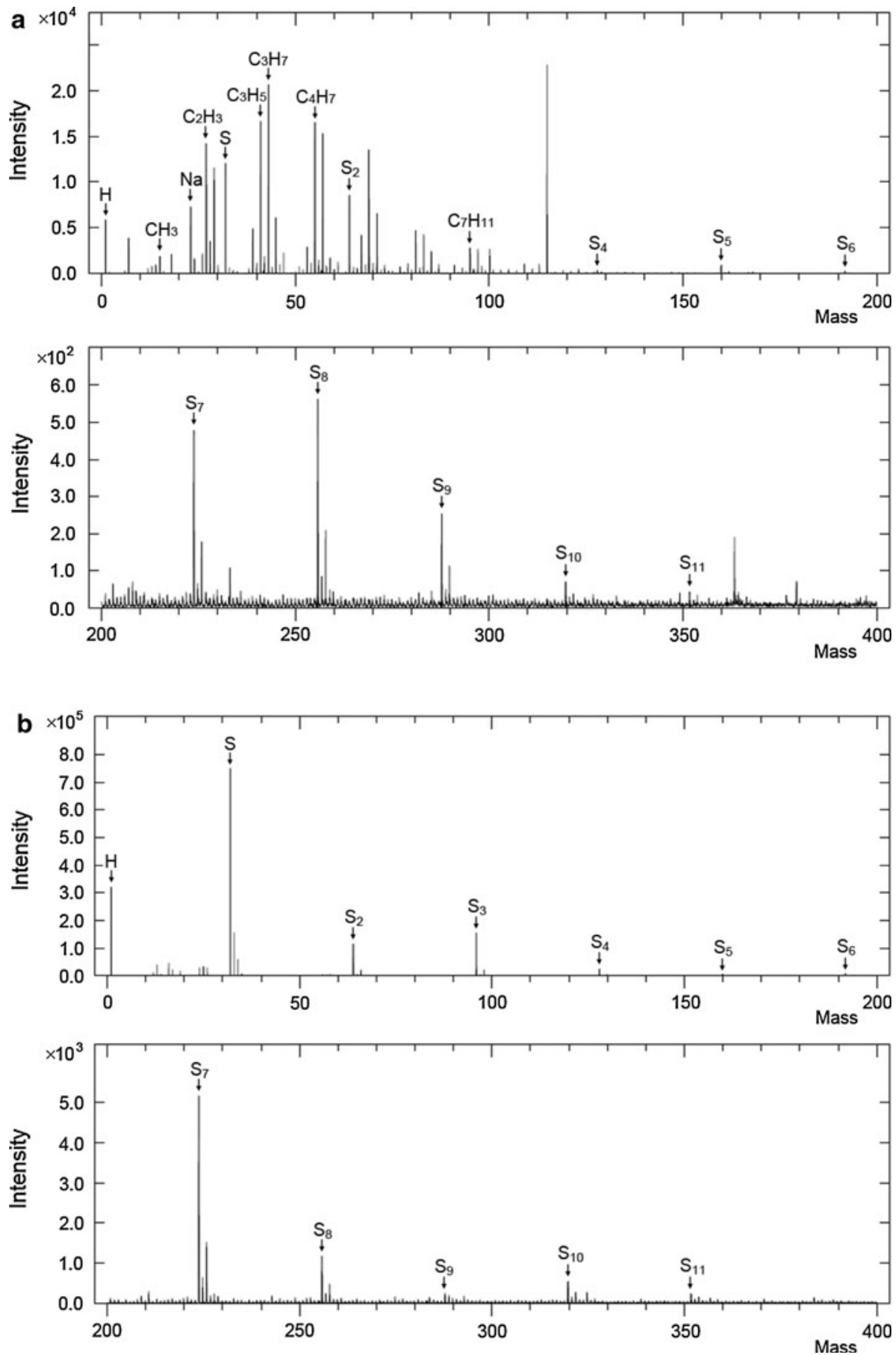

Fig. 7 a Positive ToF-SIMS spectrum of plasma acetylene treated sulfur; b Negative ToF-SIMS spectrum of plasma acetylene treated sulfur 
sulfur spectra. As a different monomer was applied, the polymer fraction peaks in the high mass range show a different pattern. The accompanying negative spectra are given in Fig. $8 \mathrm{~b}$, where the presence of the fluor peak confirms the formation of a fluor containing polymer. The surface is again not fully covered as the sulfur peaks can still be detected.

The positive and negative spectra of plasma polyacrylic acid treated sulfur ( $\mathrm{PAAS}_{8}-2$ ) are given in Fig. 9a and b, respectively. Compared to the untreated sulfur, PAAS $_{8}-2$ also shows a significantly reduced concentration of sulfur ion peaks, which is a sign of the presence of the coating. This is further evidenced by the characteristic cluster pattern of mass fragments, in the positive spectrum in Fig. 9a, especially in the higher mass fraction region from 200 to 400 . No peaks coming from oxygen are detected. The absence of oxygen in the plasma polymer can be attributed to the very high RF power applied for the polymerization process. Such a high power breaks the acrylic acid molecules into atomic species and oxygen gas is formed as a byproduct. In former research, a much lower RF power was applied so that the original structure of the monomer was better preserved [20, 21].

The presence of hydrocarbon peaks in Figs. $6 \mathrm{a}$ and $8 \mathrm{a}$ is somewhat unexpected. They should not be there. However, there is the possibility of contamination or some additive (oil) that the manufacturer has used to keep the material in powder form. Contamination can also come from absorption of dirt from the atmosphere as hydrocarbons are everywhere. Some residual hydrocarbons could have been present in the plasma reactor as well.

\section{Performance of Plasma Polymer Encapsulated Sulfur in SE Blends}

The vulcameter rheograms of all the SE blends are represented in Fig. 10. For all SE compounds vulcanized with the plasma polymer encapsulated sulfur samples, a pronounced increase in the final state of cure (maximum torque) is observed. This demonstrates that SE blends cured with plasma polymer encapsulated sulfur have a better co-vulcanization behavior.

The full stress-strain curves of the SE blends cured with untreated and treated sulfur are shown in Fig. 11. All compounds with microencapsulated sulfur show significantly improved tensile strength, elongation at break and moduli. The rupture energies, calculated from the area under the curves in Fig. 11, are given in Table 5. The highest rupture energy is measured for $\mathrm{PFHS}_{8}-2$ with an increase of $63 \%$ compared to $\mathrm{S}_{8}$.

It was shown in our previous work that the solubility of sulfur is somewhat higher in SBR than EPDM, and the difference becomes larger with increase in temperature [1]. This solubility difference acts as the driving force for sulfur to migrate from EPDM to SBR before and during vulcanization within a time scale of seconds [22]. The deposition of a polymer layer modifies the surface energy of sulfur and brings it closer to those of the rubber polymers to guarantee that significant amounts of the sulfur also are lodged in the EPDM phase during mixing.

During vulcanization sulfur is slowly released from the shell and consequently gives rise to a steady replenishment of new sulfur for the vulcanization of the EPDM-phase. This eventually results in an overall higher state of cure of the EPDM-phase than when untreated sulfur is used, which predominantly moves to the SBR-phase during the mixing stage already.

\section{Performance of Plasma Polymer Encapsulated Sulfur in NE Blends}

It has been demonstrated before that the properties of NE blends are dominated by the NBR phase which has a much shorter scorch time than the EPDM phase [23]. NBR vulcanizes so 

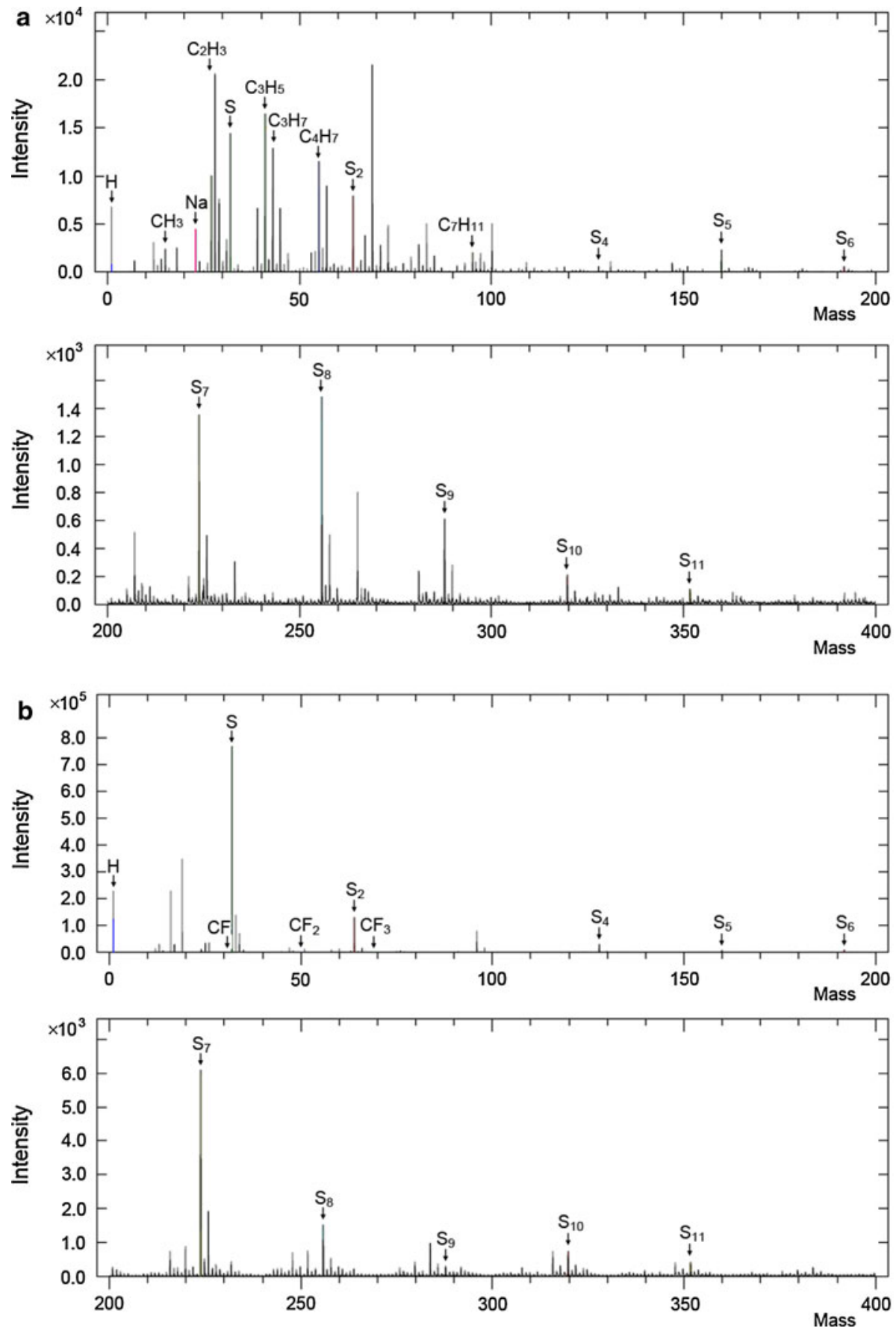

Fig. 8 a Positive ToF-SIMS spectrum of plasma perfluorohexane treated sulfur; b Negative ToF-SIMS spectrum of plasma perfluorohexane treated sulfur 

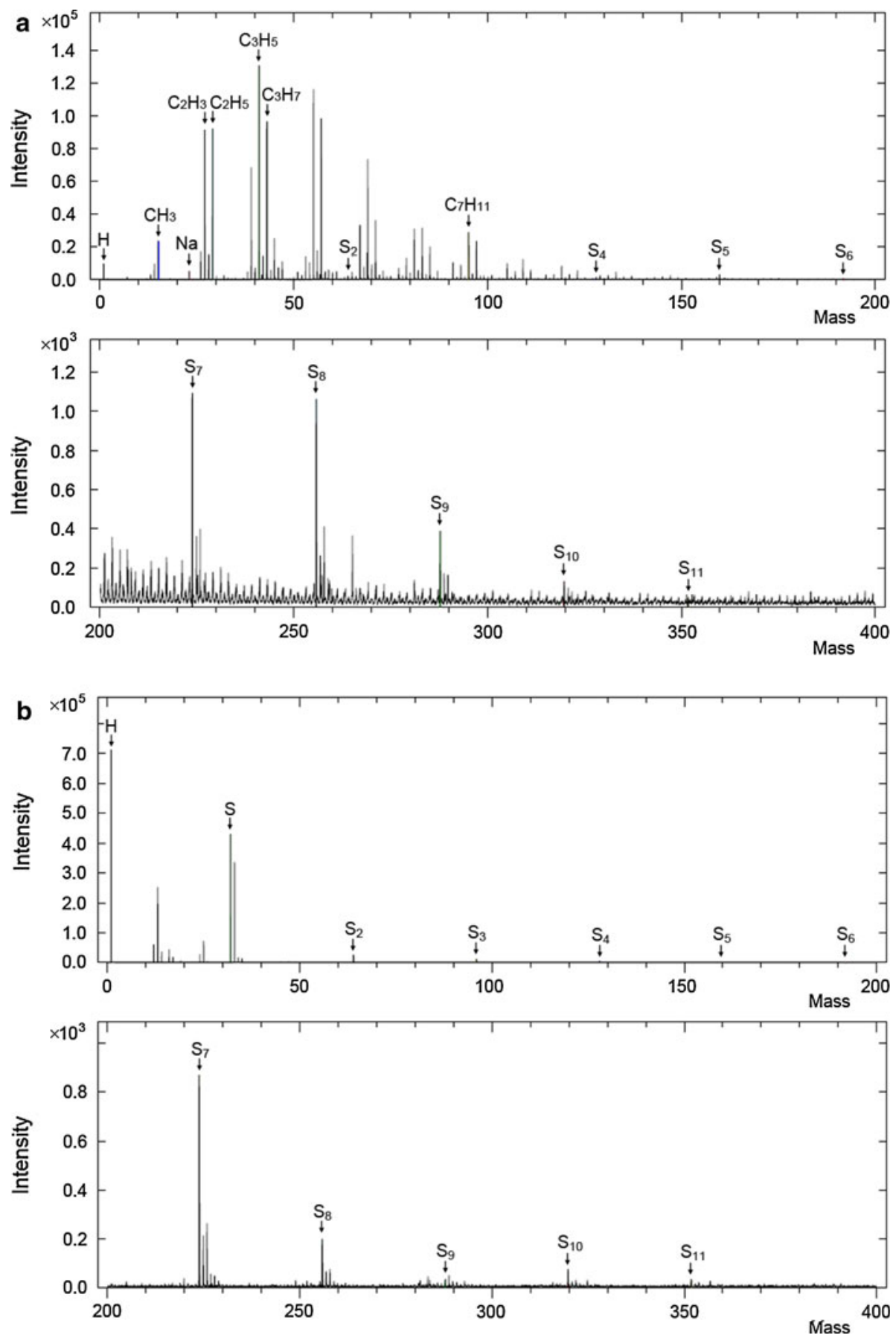

Fig. 9 a Positive ToF-SIMS spectrum of plasma acrylic acid treated sulfur; b Negative ToF-SIMS spectrum of plasma acrylic acid treated sulfur 
Fig. 10 Rheograms of the SE blends cured with: (- $\mathrm{S}_{8}$; $(\square \square)$ PPAS $_{8}-1 ;(\neg-)$. PPAS $_{8}-2 ;(\triangle \triangle)$ PPAS $_{8}-3$;

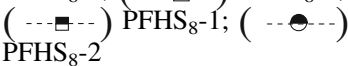

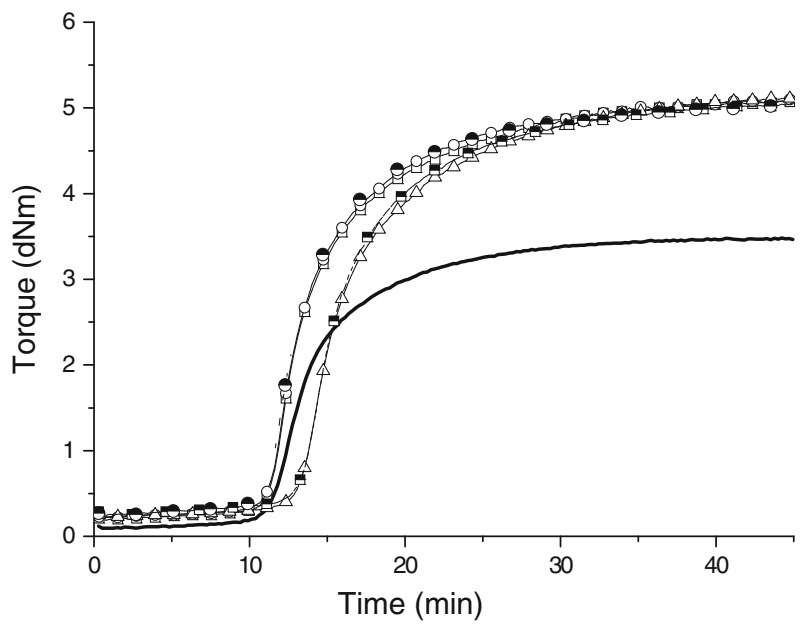

Fig. 11 Tensile curves of the SE blends cured with: symbols as in Fig. 10

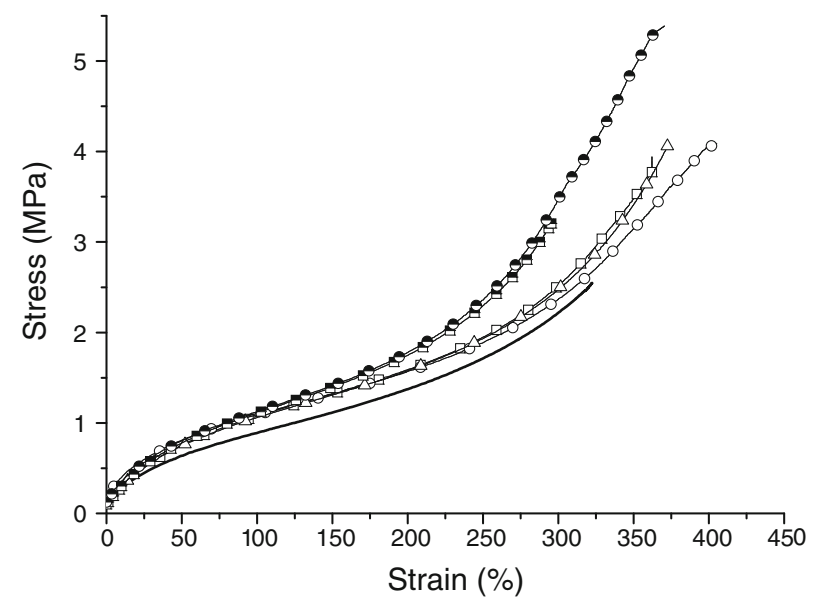

Table 5 Rupture energies of the SE blends with different sulfur samples

\begin{tabular}{lllll}
\hline Sample code & $\begin{array}{l}\text { Tensile strength } \\
(\mathrm{MPa})\end{array}$ & E.B. $(\%)$ & $\begin{array}{l}100 \% \text { Mod. } \\
(\mathrm{MPa})\end{array}$ & $\begin{array}{l}\text { Rupture energy } \\
(\text { a.u })\end{array}$ \\
\hline $\mathrm{S}_{8}$ & 2.6 & 323 & 0.9 & 399 \\
PPAS $_{8}-1$ & 5.0 & 383.5 & 1.1 & 598 \\
PPAS $_{8}-2$ & 4.3 & 378.5 & 1.1 & 631 \\
PPAS $_{8}-3$ & 4.9 & 380.2 & 1.1 & 606 \\
PFHS $_{8}-1$ & 3.2 & 297 & 1.1 & 440 \\
PFHS $_{8}-2$ & 5.1 & 341 & 1.1 & 650 \\
\hline
\end{tabular}

E.B. elongation at break, $a . u$ arbitrary units

quickly in comparison with EPDM, that curing NBR is already complete when EPDM still has to begin. Contrary to the SBR/EPDM-blend it is practically impossible to overcome this large cure mismatch for the NBR/EPDM-combination. The rheograms of all NE blends are 
Fig. 12 Rheograms of the NE blends cured with: symbols as in Fig. 10; ( - PAAS $_{8}-1$; $(\longrightarrow)$ PAAS $_{8}-2$

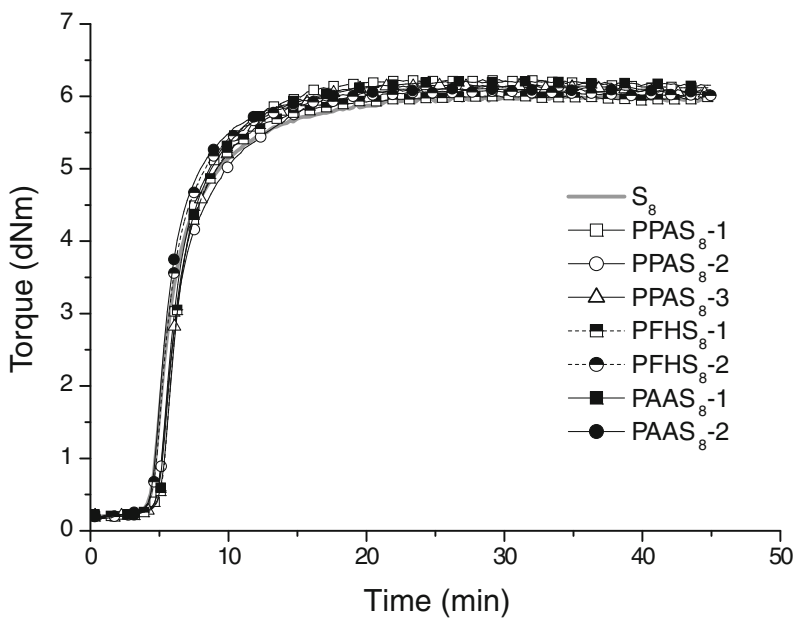

represented in Fig. 12. It can be seen that the NE blends cured with plasma polymer modified sulfur give only a marginal improvement in the maximum state of cure. The plasma acrylic acid modified sulfur has a smell of acrylic acid, which indicates the presence of a tiny amount of acid still present in the coating. However not much scorch delay is obtained, in spite of the fact that acids are well known to cause cure delay.

The tensile strength, elongation at break and $100 \%$ modulus of all NE blends are given in Fig. 13. The NE blend cured with uncoated sulfur is used as control. The plasma polyacetylene coated sulfur gives a decreased modulus and similar values for tensile strength and elongation at break. The perfluorohexane coated sulfur provides somewhat improved stressstrain properties compared to the control. The best properties are obtained for the plasma polyacrylic acid coated sulfur compared to the control. A very pronounced increase is even found for $\mathrm{PAAS}_{8}-2$, the sulfur powders treated for $2 \mathrm{~h}$. The NE vulcanizate cured with $\mathrm{PAAS}_{8}-2$ shows a two times higher tensile strength compared to the control. It also gives a much higher elongation at break. It is surprising to observe that half an hour difference in treatment time can result in such a large change in the performance of the modified sulfur.

The rupture energies, calculated by integrating the areas under the full stress-strain curves in Fig. 13, are given in Table 6. The highest increase is for $\mathrm{PAAS}_{8}-2$ with an increase of $110 \%$.

\section{Conclusions}

By applying plasma polymerization with acetylene, perfluorohexane and acrylic acid, a polymer layer is deposited on sulfur powders. The amounts of coating determined were in the range of 1.2 to $5 \%$. The surface energies of sulfur are decreased and brought closer to those of the rubber polymers: SBR, NBR and EPDM involved in this study. A better compatibility between the rubbers and sulfur is achieved by decreasing the surface energy difference.

Better co-vulcanization is achieved in the SE blends with the plasma poly-acetylene and poly-perfluorohexane microencapsulated sulfur. There are practically no appreciable improvements obtained in the NE blends by using plasma poly-acetylene and polyperfluorohexane treated sulfur. As stated in our previous study [23] it is more difficult to improve the cure mismatch in the NE blends. Therefore, acrylic acid was applied as monomer in the plasma treatment with a significant improvement in the properties of $\mathrm{NE}$ 
Fig. 13 Tensile curves of the NE blends cured with: symbols as in Fig. 12

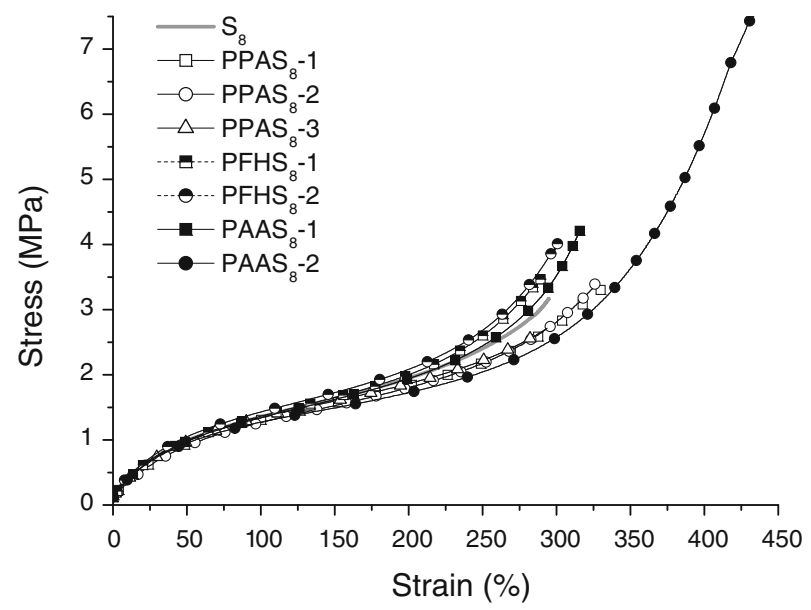

Table 6 Rupture energies of the NE blends with different sulfur samples

\begin{tabular}{lllll}
\hline Sample code & $\begin{array}{l}\text { Tensile } \\
\text { strength }(\mathrm{MPa})\end{array}$ & E.B. $(\%)$ & $\begin{array}{l}100 \% \text { Mod. } \\
(\mathrm{MPa})\end{array}$ & $\begin{array}{l}\text { Rupture energy } \\
\text { (a.u) }\end{array}$ \\
\hline $\mathrm{S}_{8}$ & 3.2 & 295 & 1.4 & 486 \\
PPAS $_{8}-1$ & 4.0 & 349 & 1.3 & 571 \\
PPAS $_{8}-2$ & 4.3 & 352 & 1.3 & 546 \\
PPAS $_{8}-3$ & 4.0 & 344 & 1.3 & 458 \\
PFHS $_{8}-1$ & 3.3 & 284 & 1.3 & 350 \\
PFHS $_{8}-2$ & 4.0 & 301 & 1.4 & 555 \\
PAAS $_{8}-1$ & 4.6 & 312 & 1.4 & 571 \\
PAAS $_{8}-2$ & 7.7 & 425 & 1.3 & 1,020
\end{tabular}

E.B. elongation at break, a.u arbitrary units

blends obtained. The very high polarity of acrylic acid favors the dispersion of treated sulfur in the NBR-phase relative to the untreated sulfur. The acidity of acrylic acid may also play a role in determining the final properties of the NE blend. Further investigations are needed to elucidate the full mechanism.

Acknowledgments This project is financially supported by the Dutch Technology Foundation (STW), the Applied Science Division of NWO, the technology program of the Ministry of Economic Affairs of the Netherlands, under project \# TPC.6079. TIMCAL Graphite and Carbon and Hexagon Compounding in Belgium are also gratefully acknowledged for their support.

Open Access This article is distributed under the terms of the Creative Commons Attribution Noncommercial License which permits any noncommercial use, distribution, and reproduction in any medium, provided the original author(s) and source are credited.

\section{References}

1. Guo R, Talma AG, Datta RN, Dierkes WK, Noordermeer JWM (2008) Eur Pol J 44:3890

2. Mark JE, Erman B, Eirich FR (2005) Science and technology of rubber: elastomer blends. 3rd edn. Elsevier, New York, p 565 
3. Ghosh AK, Debnath SC, Naskar N, Basu DK (2001) J Appl Polym Sci 81:800

4. Scares BG, Sirqueira AS, Oliveira MG, Almeida MSM (2002) Macromol Symp 189(1):45

5. Yasuda HK (2005) Plasma Process Polym 2:293

6. Inagaki N, Tasaka S, Abe H (1992) J Appl Polym Sci 46:595

7. Park SJ, Kim JS (2000) J Colloid Interf Sci 232:311

8. Park SJ, Kim JS (2001) Carbon 39:2011

9. Akovali G, Ulkem I (1999) Polymer 40:7417

10. Tricás N, Vidal-Escales E, Borrós S, Gerspacher M (2003) ISPC Proceedings, Sicilia, p. 366

11. Tricás N, Borrós S (2005) Kautsch Gummi Kunstst 58:511

12. Mathew T, Datta RN, Dierkes WK, Noordermeer JWM, van Ooij WJ (2008) Plasma Chem Plasma Process 28:273

13. T. Mathew, Ph.D. Thesis, University of Twente, Enschede, Netherlands, 2008

14. Mathew G (2004) Polym Adv Technol 15:400

15. Nah C, Huh MY, Rhee JM, Yoon TH (2002) Polymer Int 51:510

16. Tiwari M, Mathew T, Noordermeer JWM, Dierkes WK, Datta RN, Talma A, van Ooij WJ (2008) Kautsch Gummi Kunstst 61:502

17. van Ooij WJ (2003) Rubber world, August, p 1

18. Vidal E, Borros S, Agullo N, van Ooij WJ (2000) ACS rubber division meeting, Cincinnati

19. van Krevelen DW, Hoftijzer PJ (1990) Properties of polymers, 3rd edn. Elsevier, Amsterdam, p 231

20. Yasuda H (1985) Plasma polymerization, 1st edn. Academic Press, Orlando, p 179

21. van Ooij WJ private communication

22. Bird RB, Steward WE, Lightfoot EN (2007) Transport phenomena: diffusivity and the mechanisms of mass transport, 2nd edn. Wiley, New York, p 518

23. Guo R, Talma AG, Datta RN, Dierkes WK, Noordermeer JWM (2010) Macromol Mat Eng 295:199 